\title{
DISSERTATION ABSTRACTS
}

\section{DANDURAND, Lawrence, An Empirical Determination of Perceived Information Source Inten- sities, Their Interrelationships, Their Relationships Relevant to Specific Stages in a Multina- tional Decision Process, and Their Relationships to Other Factors.*}

In a dynamic era of multinational business systems, social and technological change, and information proliferation, the problem of providing useful information to multinational executives is increasing. One approach to alleviating the problem is the development of an efficient multinational management information system (MMIS).

An efficient MMIS is based on an accurate model of the executive decision process. An accurate model identifies relevant decision process variables and specifies their interrelationships.

A simple random sample of forty-eight manufacturing firms involved in international operations and located in the Missouri portion of the St. Louis Standard Metropolitan Statistical Area was selected for study. A specific decision process was divided into four sequential stages and executives responded to a comprehensive set of information source categories at each stage. A magnitude estimation technique was used to quantify executive perceptions.

Eleven research hyphotheses were tested. Findings indicate that: (1) there is a significant difference in intensities between information sources; (2) there is a significant difference in intensities between oral and non-oral sources; (3) there is a significant difference in intensities between decision stages; (4) there is a significant interaction between source and decision stage; (5) there is a significant difference in intensities between different size firms; (6) there is a significant interaction between source and enterprise size; (7) there is a significant difference in intensities between industries; ( 8 ) there is a significant difference in intensities between markets; (9) there is a significant difference in intensities between executives having different amounts of experience; and (10) there is a significant difference in intensities between firms experiencing different profit levels. The eleventh hypothesis-there is a significant difference in intensities between firms having different amounts of experience-was not confirmed.

UNIVERSITY OF MISSOURI-COLUMBIA-1975

\section{GLADWIN, Thomas Neil, The Role of Ecological Considerations in the Multinational Corpo- rate Project Planning Process: A Comparative Study of North American- and Western European-Based Petroleum, Chemicals, and Metals Firms. (Volumes I and II).*}

This study describes and explains the extent to which, and the manner in which, ecological considerations have been incorporated into multinational corporate project planning. A multidimensional construct, "ecological incorporation," is the dependent variable of the study and pertains to the effective integration of ecological considerations into the succession of activities involved in project planning. This operationalized construct consists of twenty-six indicators and is created by fusing concepts of environmental impact assessment into a behavioral model of the corporate investment planning process. A contextual model of explanation, consisting of project nature, organizational, and public policy variables, is developed from the literature on organizational innovation and organization-milieu relations.

A cross-sectional, cross-national, comparative research methodology is employed. Focused interviews using a common interview guide were conducted in nine nations with seventy-three senior, project, and environmental managers in seventeen different multinational petroleum, chemicals, and metals firms. By means of explicit categorization and scoring procedures, the raw interview data on both dependent and independent variables are converted into quantitative indices. An overall composite index of "ecological incorporation" is constructed and fifteen intensivelyexamined project planning cases are rank-ordered from the least to the most amount of observed incorporation. Rank-order correlation and partial correlation techniques are employed in the analysis of the data

The study discovers that environmental factors have been incorporated quite exiguously in some planning processes, moderately in others, and extensively in still others. Analysis of model behavior, however, leads to the conclusion that the practice of environmentally-sound project planning is still in its infancy. The extent of "ecological incorporation" embodied in a planning 
process is found to be a function of an interaction among: 1) the nature of the project, 2) the organizational context of the project planning process, and 3) the public policy context of the firm and the project being planned. Environmentally-oriented planning behavior is discovered to be strongly positively related to project-associated public pressures for environmental protection and to the cost and type of project. It is found to be moderately positively related to the firm's past environment-related conflict experience, commitment to environmentally-responsible objectives, and extent of interaction with external environmental protection organizations.

THE UNIVERSITY OF MICHIGAN-1975

\section{LOGAR, Cyril Mathew, Location of Responsibility for Product-Policy Decisions of United States-Based Multinational Firms Manufacturing Consumer Goods.*}

Presented in this dissertation were the findings of a study analyzing the location ( $100 \%$ centralized, $100 \%$ decentralized, or joint) of responsibility for international product-policy decisions of United States-based multinational corporations manufacturing and selling consumer durable or consumer nondurable goods in developed and/or less-developed countries. The objectives of the study were: 1 . To determine whether the decision-making responsibility concerning overseas productpolicy decisions are totally centralized, decentralized, or joint. 2. To determine which factors were considered by the parent company when decisions to centralize and/or decentralize international product-policy decisions are made.

For purposes of obtaining the data, a highly structured mail questionnaire was mailed to 195 multinational corporations.

Sixty, or 31 per cent, of the multinational corporation executives included in the study completed the questionnaire. Eight hypotheses were statistically tested in the study. It was hypothesized that the degree of decentralization (location of responsibility) for product-policy decisions of multinational corporations manufacturing and selling consumer durable or nondurable goods in developed and/or less-developed countries varies significantly with: 1. subsidiaries located in developed versus less-developed countries; 2 . durable versus nondurable goods; 3 . the total gross sales of the corporation; 4. the per cent of total sales that are not domestic; 5 . the per cent of total sales that are from developed countries; 6 . the per cent of total sales that are from less-developed countries; 7 . the type of corporate organizational structure and, 8 . the type of product-policy decision.

The results show that the location of responsibility of international product-policy decisions in the sixty responding United States-based multinational corporations is primarily centralized regardless of the level of country development.

KENT STATE UNIVERSITY-1975

\section{JACKSON, Graham I., British Retailers' Expansion into Europe.}

This study concerns the problems, techniques, and solutions involved when British retailers expand into continental Europe. Some fifty-six firms have been involved in a total of 169 different entries into various countries; and most of the activity occurred since 1970

Any firm engaged in retailing has certain features which distinguish it from firms in either the primary or secondary sectors of industry. To identify the special characteristics of retailers, it is useful to recognize that the elements which go to make up the Retail Formula are but the manifest expression of an underlying Business Idea. The Business Idea is the structural and dynamic basis upon which the Retail Formula can be adapted in a consistent way to changes which occur in the environment.

The concept of Business Idea forms the main starting point for the analysis of retailers' motives for expanding abroad, the main stimuli and premises, the decision-making process for investigating and choosing markets, the broad strategies which are possible, and the four main expansion tactics.

Whenever the retailing firm expands abroad some changes are made in the Retail Formula of the foreign subsidiary. The thesis examines the question whether it is sufficient merely to change the 
Retail Formula or whether success depends on adapting the whole Business Idea to the new environment. This leads on to analysis of the allocation of responsibility for making changes and managing the differences between the parent and subsidiary. A stage by stage study of performance is undertaken, showing how targets are chosen, and how firms' experiences range from the relatively straightforward, to the highly problematic. An overview of the expansion of British retail expansion is developed, which allows all the moves so far made, plus the subsequent penetration, to be categorized and compared. The emerging trends are now for those firms which are already operating in Europe to build on existing footholds, expand into more European countries, and to start to spread worldwide.

THE UNIVERSITY OF MANCHESTER INSTITUTE OF SCIENCE AND TECHNOLOGY_Manchester, England-1976

\section{SACHDEV, Jagdish C., A Framework for the Planning of Disinvestment Policies for Multina- tional Companies.}

The subject of foreign disinvestment is a relatively recent phenomenon which has its roots in the development of present day multinational corporations.

Disinvestment experience of foreign manufacturing operations by British multinationals indicates that the financial performance of a particular foreign operation has been used by management as a major decision-making criterion. Although the tendency towards involuntary disinvestment is higher in developing countries, the developed nations are equally sensitive to disinvestment on a voluntary basis. This is accounted for by the fact that industries employing high technology are mainly centered in developed countries where obsolescence is substantially high. This area of research is in rather a rudimentary stage when compared to studies already undertaken into the various activities of multinationals. It is timely to suggest, however, that the whole element of the disinvestment phenomenon within the context of development and efficient international resource allocation should be undertaken. The idea of voluntarily planned or built-in disinvestment of foreign operations previously met with greater support from the host nations. More recently, the emphasis is that increasing numbers of multinationals are laying stress upon the implementation of planned or built-in disinvestment policies. More importantly, issues of management control, corporate ownership, and the objectives of the host nations and multinationals need to be better clarified.

Past experience of foreign disinvestment suggests that in the future multinationals will be more concerned with the rationalization and consolidation of their existing foreign operations rather than with the question of indiscreet expansion.

THE UNIVERSITY OF MANCHESTER INSTITUTE OF SCIENCE AND TECHNOLOGY_Manchester, England-1976

\section{TOWNSEND, James B. Colonel, The Sherman Act and the U.S. Multinational Corporation.}

This dissertation examines the influence of the Sherman Antitrust Act on the market-entry strategy of United States multinational corporations (USMNCs). Exact definitions of its provisions and its precise application to American foreign trade have been entrusted to the courts. This has caused American business to allege that the Act inhibits its foreign business operations and makes it less competitive in world markets since foreign competitors are not similarly encumbered.

The legal foundations of antitrust are considered, along with antitrust precedents and landmark cases figuring in extraterritorial jurisdiction. The rules of extraterritorial antitrust are applied to the general ways in which a USMNC may do business abroad-export, ownership, or license. The theoretical considerations of the law are then compared with actual USMNC experiences to determine the effect of the Sherman Act on USMNC market-entry strategy. The interaction of the public interest and the law is also assessed.

The research found that extraterritorial application of the Sherman Act generally nullified the market-entry strategy of USMNCs engaged in manufacturing. Either there was no chance for an alternative strategy of maiket entry, or else it was clear that a different strategy would bring the same results. Where the law had an effect, four times out of five it had an immediate and direct 
impact on USMNC market-entry intentions. The effect on licensing as a strategy of market entry was most noticeable, followed, in order, by the effect on ownership and then on exports. Antitrust caused companies to either not enter markets alone or to forego opportunities to do so with others. The indirect effects were few and were apparent only after market entry. It was also found that business has been either reluctant or unable to furnish the facts which would tend to confirm the contention that the Sherman Act is injurious to American business abroad and, therefore, should in some way be modified.

It was concluded that there is evidence, presumptive but not conclusive, that the extraterritorial application of the Sherman Act adversely affects American business abroad. It was also concluded that there is insufficient justification at this time to suggest a reexamination of present antitrust policy.

GEORGE WASHINGTON UNIVERSITY-1976

\section{AGGARWAL, Raj Kumar, The Management of Foreign Exchange: Optimal Policies for a Multinational Company.*}

This study examined the risks of loss faced by a multinational company (MNC) because of frequent unexpected changes in exchange rates and then developed a control-limit model for implementing MNC policies for the management of foreign exchange. This subject has become especially important for MNCs since the currencies of major industrialized countries started floating. Because of the importance of MNC-related international monetary flows, MNC policies in this area also have important implications for central and commercial bankers.

The study examined 27 other empirically-based studies of MNC policies for the management of foreign exchange that contained data from over 800 company-surveys and the data from 16 structured in-depth interviews with selected MNC-related professionals.

The three main results of this study are: (a) an improved conceptual framework for the MNC management of foreign exchange resulting from a redefinition of the problem, (b) a clarification of the concept of MNC exposure to exchange losses, and (c) a new model for the MNC management of foreign exchange applicable even to companies in which the foreign subsidiary is treated as an independent profit center.

KENT STATE UNIVERSITY-1975

HOELSCHER, David Hunter Stockton, Investment and Capital Structure in the International Firm: Theoretical and Empirical Analysis.*

The international firm is usually analyzed with models developed for single currency firms. Key features of that model include the separation of financial and investment decisions (following the work of Modigliani and Miller) and the assumption that the parent's demand for return on investment is the principal determinant of capital repatriation. The model developed in this study breaks from that tradition in several significant ways. It is shown that investment and financial decisions are determined simultaneously rather than independently. A structural model is developed showing this relationship. The two financial activities studied are borrowing in the host capital market and capital transfers to the parent (broadly defined to include profit repatriation and payments of dividends, royalties, and fees to the parent).

Three principal hypotheses are developed. First, it is argued that liquidity factors play a significant role in determining subsidiary investment behavior. Second, the subsidiary's financial policy is described as an effort at firm-wide cash management. Finally, capital transfers are described in terms of stock-flow adjustment policies. The model is tested with cross-sectional data

The model performs quite well using data from manufacturing subsidiaries in developed countries. Support is found for all three hypotheses for that sample. Severe data limitations and small degrees of freedom make it difficult to test the model using data from less developed countries and from the petroleum sector. Nevertheless, support for the first and third hypotheses is found when the model is estimated with data from each sample, except in the case of petroleum subsidiaries in developed countries. 


\title{
KATCHER, Max, An Analysis of the Effectiveness of the Overseas Trade Fair Program of the United States Department of Commerce as an Export Promotion.*
}

The general objective of this study was to assess the effectiveness of the Department of Commerce's (DOC) foreign exhibitions program as an instrument of export promotion of American industrial products.

The major findings are summarized as follows: (1) The principal objectives for participating in the overseas fair program were the same for most American firms, with exposure in a foreign market as the primary objective, and finding sales representatives or distributors and immediate floor sales the other significant objectives. (2) The majority of companies achieved their most important objectives, and neither company size nor industry type determined the extent to which these objectives were achieved; however, the initial participant appeared to achieve objectives less fully than the more frequent participant. (3) The majority of firms reported that DOC's conduct of the program was good; no industry criticized the program significantly more than any other industry. The criticism most frequently cited by the minority was over-optimism of market potential by DOC. (4) American firms that participated in the program strongly favored continuation in the program, regardless of their size or industry type; but firms with a high proportion of foreign sales appeared more interested in exhibiting under the program than firms with a low foreign sales mix. A majority of firms also expressed willingness to exhibit in nongovernment supported foreign exhibitions. (5) It was found that firms were indifferent with regard to direct foreign investment or exporting as their long-range goal, thus a significant number of firms which participated in DOC's overseas trade fair program showed interest in developing manufacturing facilities in foreign countries.

THE GEORGE WASHINGTON UNIVERSITY-1975

\author{
MACALUSO, Donald G., The Financial Advantage of Multinational Firms During Tight Credit \\ Periods in Host Countries.*
}

An overall advantage over foreign competition (stemming from technology, marketing, management depth, size, etc.) is a necessary condition for successful foreign operations. Such advantages have contributed to the secularly rising share of U.S. foreign direct investment in the total capital formation of many host countries.

One of these advantages is the ability of affiliates of multinational firms to circumvent restrictive monetary policies in host countries more readily than host-country (local) firms.

The purpose of this study is to seek empirical evidence regarding the process of circumventing host-country monetary restrictions and the result of this process.

The so-called "financial escape" hypothesis is tested by regression analysis for six host countries (Canada, the United Kingdom, France, Germany, Japan, and Belgium) during the period 1960-71. This was a period of rapid growth of foreign direct investment in these countries. Data availability limited the investigation to U.S. FDI, but the findings should apply to FDI in general because (a) U.S. FDI comprised the bulk of FDI in the subject countries, and (B) there is evidence that FDI of all nationalities display similar financial and investment behavior.

The findings validated the hypothesis. In every country, but Japan, the posited adjustments in sources of funds accompanied increased affiliate shares of fixed capital formation in association with periods of restricted credit. For Japan, increases in the affiliates' share of fixed capital were not accompanied by parallel adjustments in the sources of funds investigated.

The findings are consistent with prevailing national policies, which, except for Japan, were neither particularly restrictive nor discriminatory against MNC affiliates. Indeed, every country, but Japan, solicited and subsidized (for siting in lagging regions and for generating exports) FDI, particularly U.S. FDI.

NEW YORK UNIVERSITY, GRADUATE SCHOOL OF BUSINESS ADMINISTRATION-1975. 
DE BODINAT, Henri, Influence in the Multinational Corporation.

The influence of the parent companies of multinational corporations on their foreign subsidiaries has not been studied so far in depth.

The goal of this thesis is to fill that gap. But because of the complexity and width and unexplored character of the phenomenon, this thesis is only an exploratory step. This exploration might, itself, be subdivided into two stages. First, an attempt to grasp the phenomenon of parent's influence on the subsidiary itself to discover its main characteristics. Second, an attempt to develop hypotheses concerning the reasons why influence is more intense in a multinational firm than in another one.

The first step has permitted to establish that influence could be analyzed along several dimensions. Influence is characterized by a multiplicity of goals (namely, coordinate, reduce slack, and transmit knowledge), of methods (influence can be direct or indirect), of channels (formal or informal), or directions (influence can be top-down, but also bottom-up, or even lateral, i.e., one subsidiary might influence another one). However, in spite of this complexity and ambiguity, it is possible to compare firms in terms of influence in a fairly rigorous way. In this thesis a precise method is proposed.

The second step has given a set of hypotheses concerning the reasons why there is more or less influence in a firm. The thrust of the research was that the degree of influence was not the result of a so-called and vague "corporate philosophy", but has strong connections with the characteristics of the firm and of its environment.

It seems that these preliminary hypotheses on the relationships between the characteristics of the MNCs and the influence existing in it could be tentatively generalized to other social systems, especially national economic systems.

HARVARD UNIVERSITY, GRADUATE SCHOOL OF BUSINESS ADMINISTRATION-1976

DUBIN, Michael, Foreign Acquisitions and the Spread of the Multinational firm.

While the behavior of multinational firms has been extensively researched in recent years, little substantive conceptual foundation has been laid for cross-border acquisitions, particularly from a micro-economic point of view. The question is not unimportant as nearly fifty per cent of all manufacturing subsidiaries established abroad by U.S. firms have been acquired.

This study concludes that two characteristics of acquisitions are of systematic importance in the foreign investment decision: first, is the ability to reduce the perceived level of risk, and second, is the capacity to effect speedy transfer to foreign operations of highly developed, but underutilized, parent skills.

For total sample, the rate of acquisitions among foreign subsidiaries showed a generally rising trend over time, increasing sharply in the late 1960s, with some cyclical peaks and troughs corresponding to cycles in acquisition activity in the United States. The most remarkable conclusion of the study was that, acting counter to this trend, was the systematic influence of parent size on the acquisition rate. The larger and more experienced that firms became, the less frequently acquisitions were used in expanding abroad. It was the small firms, relatively inexperienced abroad, that turned actively to acquisitions. The ability of acquisitions to reduce the overall corporate risk in the foreign investment decision was a critical factor underlying this behavior.

The results suggest that managers' calculations ex ante are consistent with a profit-maximizing view of the firm, rather than alternative behavioral models, such as growth maximization. A worldwide view of the parent system that enables the decision maker to measure the marginal impact of an incremental investment on the system's overall risk and return is essential to evaluating foreign acquisition decisions. Various prospects and pitfalls facing the acquisition decision are discussed. The implications for host country policies include the potential to design incentive schemes using selective accessibility to acquisitions of local firms as a means of encouraging foreign investment.

HARVARD UNIVERSITY, GRADUATE SCHOOL OF BUSINESS ADMINISTRATION-1976 


\section{GHADAR, Fariborz, A Study of the Evolution of Strategy in Petroleum Exporting Nations.}

This thesis is a study of the development and growth of National Oil Companies (NOC) in developing oil exporting nations. From three intensive oil industry case studies (Iran, Saudi Arabia, and Indonesia) it is concluded that similarities exist in the development of these national oil companies, making it appropriate to describe and categorize their historical growth by using three stages of development. Each stage of development from a small information gathering entity to when the NOC becomes its government's economic and developmental arm, embodies its own constraints, opportunities, and sets of conflicts: between the local government and the foreignowned enterprise, the local government and the NOC, and the foreign-owned enterprise and the NOC.

Local marketing was the first operation taken over by NOC, followed by local refinery, and finally by local production. Although it was established that the degree to which these three barriers to entry were present was detrimental to the NOC's undertaking and ownership of oil operations, my attempts to measure the relative importance of the erosion of these barriers to entry were inconclusive due to the interrelated nature of these barriers themselves.

Finally after looking at the various historical paths followed by the other companies with excess crude as they attempted to sell their crude in the multinational markets, the various probable paths that different NOCs will follow as they become multinational were projected. These various paths followed will influence the NOC's structure, their roles within their own government, their attitude about ventures with other oil companies and finally the influence of OPEC as a transnational entity originally set up to safeguard their own governments' revenues.

HARVARD UNIVERSITY, GRADUATE SCHOOL OF BUSINESS ADMINISTRATION-1976

* Indicates permission to print abstract has been granted by Xerox University Microfilms International. 